\title{
Adsorption and Equilibrium Studies on the Removal of Methyl Red from Aqueous Solution Using White Potato Peel Powder
}

\author{
Conrad K. Enenebeaku ${ }^{1, a *}$, Nnaemeka J. Okorocha, b, \\ Enenebeaku E. Uchechi ${ }^{3, c}$, Ikechukwu C. Ukaga ${ }^{4, d}$ \\ ${ }^{1,2,4}$ Department of Chemistry, Federal University of Technology, P.M.B 1526, Owerri, Nigeria. \\ ${ }^{3}$ Department of Biotechnology, Federal University of Technology, P.M.B 1526, Owerri, Nigeria. \\ aenecon92002@yahoo.com, bemybeck@yahoo.com, 'ucheodionye@yahoo.com, \\ dikechris2002@yahoo.com
}

Keywords: white potato peel powder, methyl red, isotherm, Adsorption

\begin{abstract}
The potential of white potato peel powder for the removal of methyl red (MR) dye from aqueous solution was investigated. The adsorbent was characterized by FTIR and SEM analysis. Batch adsorption studies were conducted and various parameters such as contact time, adsorbent dosage, initial dye concentration, $\mathrm{pH}$ and temperature were studied to observe their effects in the dye adsorption process. The optimum conditions for the adsorption of MR onto the adsorbent (WPPP) was found to be contact (80 mins), $\mathrm{pH}(2)$ and temperature (303 K) for an initial MR dye concentration of $50 \mathrm{mg} / \mathrm{l}$ and adsorbent dose of $1.0 \mathrm{~g}$. The experimental equilibrium adsorption data of the (MR) dye fitted best and well to the Freundlich isotherm model. The maximum adsorption capacity was found to be $30.48 \mathrm{mg} / \mathrm{g}$ for the adsorption of MR. The kinetic data conforms to the pseudo-second order kinetic model.
\end{abstract}

\section{Introduction}

Dyes are natural or synthetic coloured organic compounds having the property of imparting their colour to substances such as textile, fibers, cotton etc. Numerous numbers of synthetic dyes are widely used in various industries such as textile, leather, printing, cosmetics, food, paints, rubber, plastic, pesticide and pharmaceutical industries etc for different purposes. Among these industries, textile industries are the largest producers of dye effluents compared to the other industries $[1,2]$.

Industrial effluents from these industries are one of the major causes of environmental pollution. Effluents discharged from the dyeing industries are highly coloured with huge amount of suspended organic solid which maybe toxic, mutagenic or carcinogenic [3-5]. Other harmful effects of dyes have been extensively reviewed [6-8]. The discharge of these untreated coloured effluents into receiving water bodies may either cause damages in aquatic or human lives [9]. The discharge of the untreated industrial effluents is disturbing. It is therefore necessary to remove these dyes from the effluents (wastewater) with suitable technology before discharging it into receiving water bodies.

Over the past few decades, conventional waste water treatment methods for removing dyes include biological (aerobic and anaerobic), chemical and physiochemical methods such as coagulation and flocculation, solvent extraction, membrane filtration ozonation, ion exchange, electrochemical techniques, fungal decolonization and adsorption [10-13]. The removal of dyes from wastewater or industrial effluent using adsorption method has recently gained more favour than the other methods of removal of dyes. Adsorption process has simplicity of design, more efficient, easy to operate, insensitive to toxic substances and cost effective. It therefore provides an alternative method to other expensive existing physical/ chemical/ biological methods for the removal of dyes from industrial effluents or waste water [14].

Activated carbon has been widely used as an effective adsorbent for the removal of dyes from waste water or aqueous solutions due to its high adsorption capacity; but however, the cost of production and regeneration are very high and this has limited it application for pollution control processes. In recent year there has been increasing interest in the use of low cost agricultural 
materials as adsorbent for the removal of industrial effluents or waste water. A number of investigations for the removal of dyes from aqueous solution have been carried out using low cost agricultural materials as adsorbent [15-18]. However, research interest into production of more new economical, easily available and highly efficient adsorbents are still under development. For this reason, this study was undertaken to investigate the possibility of the removal of methyl red from aqueous solutions (dye effluents).

\section{Experimental}

\section{Adsorbents collection and Preparation.}

The white potato peels were collected from Federal University of Technology Owerri (FUTO) market and its environs in Owerri West Local Government Area of Imo State, Nigeria. These agricultural wastes (white potato peels, WPP) were properly washed with running water to remove sand, dirt and other impurities present in them and is dried in an oven (at $50^{\circ} \mathrm{C}$ ) until all moistures were removed. The dried samples were ground in a mill and sieved in a sieve shaker of particle size $300 \mu \mathrm{m}$. The samples that passed through the sieve were stored in separate air tight containers labelled WPPP and used as adsorbents without any further pretreatment.

\section{Preparation of Adsorbates Solution}

Stock solution of the dye (Methyl red) was prepared by dissolving $1 \mathrm{~g}$ of the powdered dye in $1 \mathrm{~L}$ distilled water respectively to have $1000 \mathrm{mg} / \mathrm{L}$ dye concentration in the solutions. Experimental dye solutions of desired concentrations were obtained by appropriate dilution of each stock solution.

\section{Adsorbent characterization}

Fourier transform infra-red (FTIR) spectrophotometer was used to identify the different functional groups available on the adsorbent sites. The FTIR of the adsorbent was taken before and after adsorption of methyl red using FTIR spectrophotometer (Shimadzu-8400S). The adsorbent was encapsulated with $\mathrm{KBr}$ spectroscopy grade and by introducing the mix in a piston's cell of a hydraulic pump with compression pressure $15 \mathrm{KPa} / \mathrm{cm}^{2}$, the solid translucent disk was obtained. The FTIR spectrum was then recorded within the wave number range $4000-500 \mathrm{~cm}^{-1}$. In addition, surface morphology and texture of the adsorbent was analyzed using scanning electron microscope (SEM) (Model-PHENOM ProX). Prior to scanning, some quantity of the adsorbent was placed on a double adhesive sticker placed in a sputter machine for $5 \mathrm{sec}$; this gave the adsorbent a conductive property. Sample (adsorbent) stud was fixed on a charge reduction sample holder, and then was charged in the SEM machine.

\section{Batch Adsorption Study}

Adsorption parameters studied:

- Contact times are $(20,40,60,80,100,120)$ minutes

- Adsorbent dosages are $(0.5,1,2,3,4) \mathrm{g}$.

- Solution $\mathrm{pH}(2,4,6,8,10$ obtained by introducing $0.1 \mathrm{M} \mathrm{HCl}$ or $\mathrm{NaOH}$ solution into the dye solution and measuring with a DEEP VERSION model (EI pH meter)

- Initial dye concentrations are $(25,50,75,100,125) \mathrm{mg} / \mathrm{L}$.

- $\quad$ Temperatures are $(30,40,50,60,70){ }^{0} \mathrm{C}$

\section{Experimental procedure}

All batch experiments on the effects of the studied parameters on the adsorption of methyl red onto potato peels were performed according to previous works of [19] and [20]. $1 \mathrm{~g}$ of the adsorbent (WPP) was weighed in a set of conical flasks of $(250 \mathrm{ml})$ each. $100 \mathrm{ml}$ of methyl red solution of concentration $50 \mathrm{mg} / \mathrm{L}$ were measured into the different sets of flask for different dosages, times, concentrations, $\mathrm{pH}$, and temperatures. The flasks were tightly covered and agitated on a rotary shaker $(100 \mathrm{rpm})$ for $120 \mathrm{mins}$ and at room temperature $\left(27^{0} \mathrm{C}\right)$. The concentration in the 
supernatant solution was analyzed using UV-visible Spectrophotometer. The adsorption capacity of the methyl red dye was calculated using the following general formula: $[15,19,20]$

$$
q_{\theta}=\frac{\left(C_{o}-C_{\theta}\right) V}{M}
$$

where $q_{\mathrm{e}}$ is the amount of methyl red adsorbed at equilibrium per unit weight of sorbent $(\mathrm{mg} / \mathrm{g}), C \mathrm{o}$ and $C e(\mathrm{mg} / \mathrm{L})$ are the dye concentrations in the solution before and after adsorption, $V$ is the solution volume (in liter (L), and $M$ is the amount of sorbent (in gram (g) used in the adsorption experiment.

The dye percent removal (\%) was calculated using the following equation

$\%$ Dye Removal $=\frac{\left(C_{0}-C_{\varepsilon}\right) V}{C_{0}} \times 100$

\section{Results and Discussion}

\section{Effect of contact time}

To investigate the effect of contact time on the percentage removal of methyl red dyes onto WPP, an experiment was carried out by mixing $100 \mathrm{ml}$ of methyl red solution of $50 \mathrm{mg} / \mathrm{L}$ concentration with $1 \mathrm{~g}$ of WPPP adsorbent for $(10,20,40,60,80,100,120)$ min with agitation speed of $100(\mathrm{rpm})$ at $27^{\circ} \mathrm{C}$.

The effect of contact time on the percentage removal of methyl red onto WPPP is shown in Fig.1. It is observed that the sorption of methyl red dye by WPP was rapid in the initial stages and becomes slow in later stages until the optimum adsorption (equilibrium time) at 80 minutes. It can be inferred from the rapid sorption at the initial stages that there were abundance of active sites on the external surface of WPP which resulted in the rapid dye removal from the solution. The slower rate at the later stages could be attributed to the dyes being diffused into the interior of the adsorbents [21].

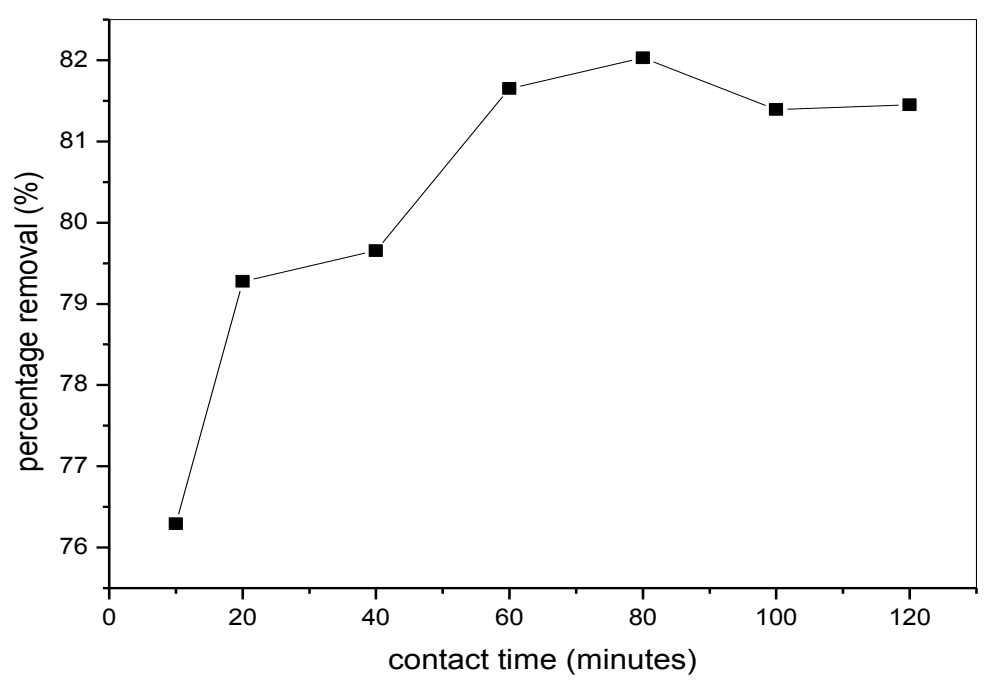

Figure 1. Effect of contact time on the adsorption of MR onto WPPP.

\section{Effect of adsorbent dosage}

The effect of adsorbent dosage on the adsorption of methyl red was carried out with methyl red dye concentration of $50 \mathrm{mg} / \mathrm{L}$ at different adsorbent dosages (0.5-4) $\mathrm{g}$, and at a fixed agitation speed $(100 \mathrm{rpm})$ at a contact time of optimum adsorption $(80 \mathrm{~min})$. The results obtained from this study are presented in Fig. 2. The percentage removal of MR dye increased from $56.17 \%$ to 
$86.58 \%$. While the adsorption capacity of the dye decreased from 5.62 to $1.08 \mathrm{mg} / \mathrm{g}$ (figure not shown) as the dosage increased from 0.5 to $1 \mathrm{~g}$. It is observed that as the adsorbent dosage increased, the amount of dyes adsorbed decreased while the percentage removal of the dyes increased. This decrease in adsorption capacity with increase in adsorbent dose is mainly attributed to nonsaturation of the adsorption sites during the adsorption process [21]. The increase in percentage removal of the dye with increase in adsorbent dose maybe attributed to increased adsorption surface area and availability of more adsorption sites which increased with increase in adsorbent dose $[22,23]$.

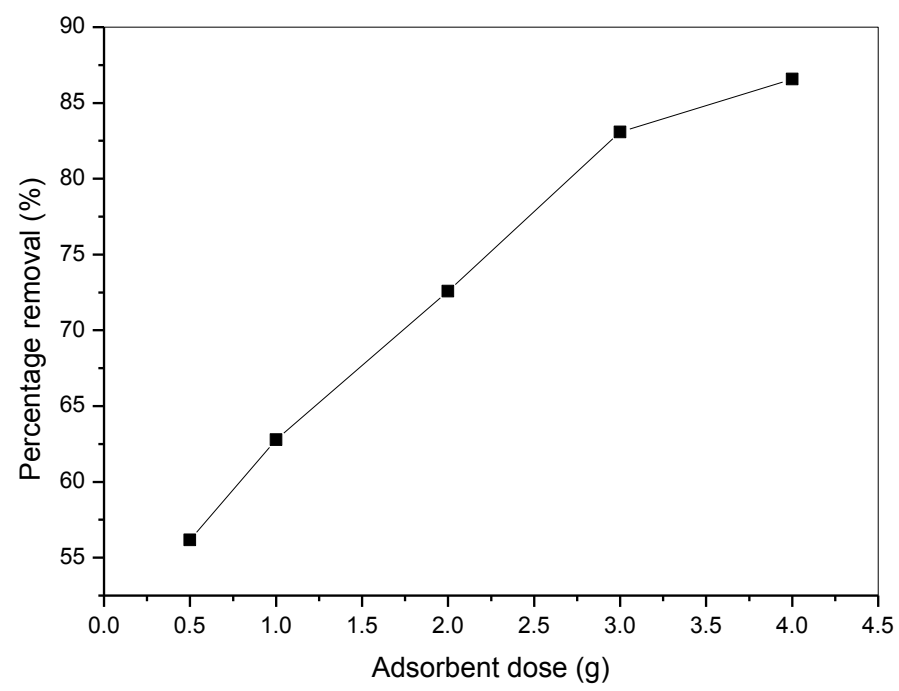

Figure 2. Effect of adsorbent dosage on the adsorption of MR onto WPPP.

\section{Effect of Initial concentration of MR}

Several standards of the methyl red dye solutions of $25,50,75,100$ and $125 \mathrm{mg} / \mathrm{L}$ were prepared from the stock solution. $100 \mathrm{ml}$ of each of the solution was added to accurately weighed $1 \mathrm{~g}$ of the different solutions and agitated at contact time of optimum adsorption ( 80 minutes) and at room temperature $\left(27^{0} \mathrm{C}\right)$.

The percentage dye removal of MR is plotted against the initial dye concentration as shown in Fig. 3. It can be observed that the adsorption capacity of dye increased from 2.09 to $10.80 \mathrm{mg} / \mathrm{g}$. While the percentage removal of the dye decreased from 91.94 to $66.14 \%$ as initial concentration increased from 25 to $125 \mathrm{mg} / \mathrm{L}$. The increase in adsorption capacity (figure not shown) with increase in initial concentration is due to the high driving force which overcomes the mass transfer resistance at higher initial dye concentration [24]. The decrease in percentage removal with increase in dye concentration maybe attributed to the fact that a given mass of adsorbent has a specific or fixed amount of dye it can absorb. Thus, this implies that, the higher the concentration of the dye, the smaller the percentage it can remove [25].

\section{Effect of temperature}

The effect of temperature on the percentage removal of methyl red onto WPPP is shown in Fig. 4. The percentage removal and adsorption capacity (figure not shown) decreased from $86.81 \%$ to $77.04 \%$ and $4.03 \mathrm{mg} / \mathrm{g}$ to $3.85 \mathrm{mg} / \mathrm{g}$ respectively as the temperature increased from 30 to $70^{\circ} \mathrm{C}$. This decrease in adsorption capacity and efficiency with increase in temperature maybe attributed mainly to the fact that the physical bonding between the dye (adsorbate) and the active sites of the adsorbent is weakened as the temperature rises. In addition, the dye solubility increases also, causing the interaction between the solute and solvent to become stronger than that between the solute and adsorbent. This therefore, makes it more difficult for the solute (ie dye) to adsorb [26]. 


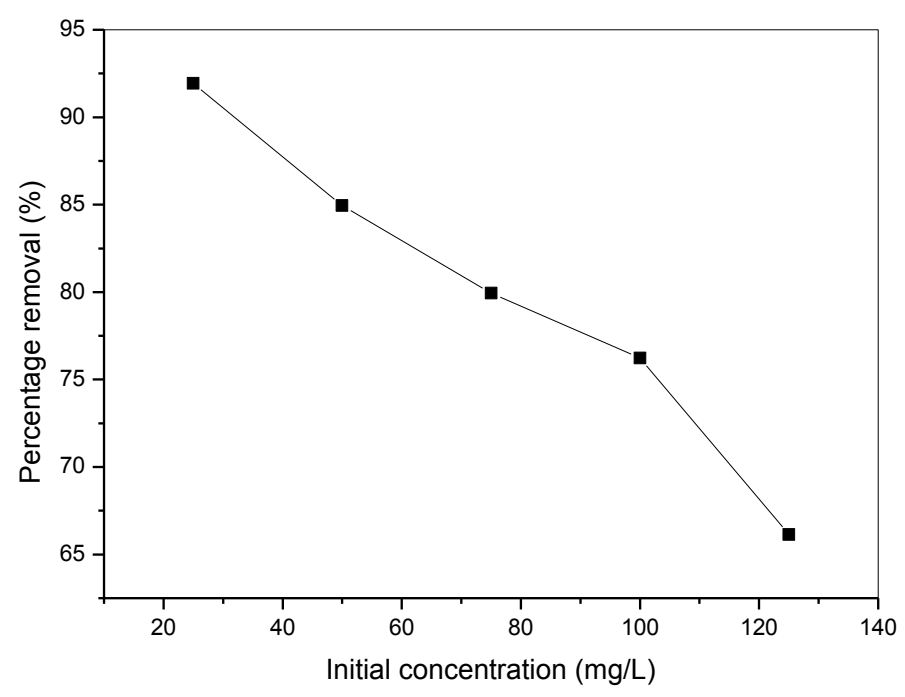

Figure 3. Effect of initial concentration on the adsorption of MR onto WPPP.

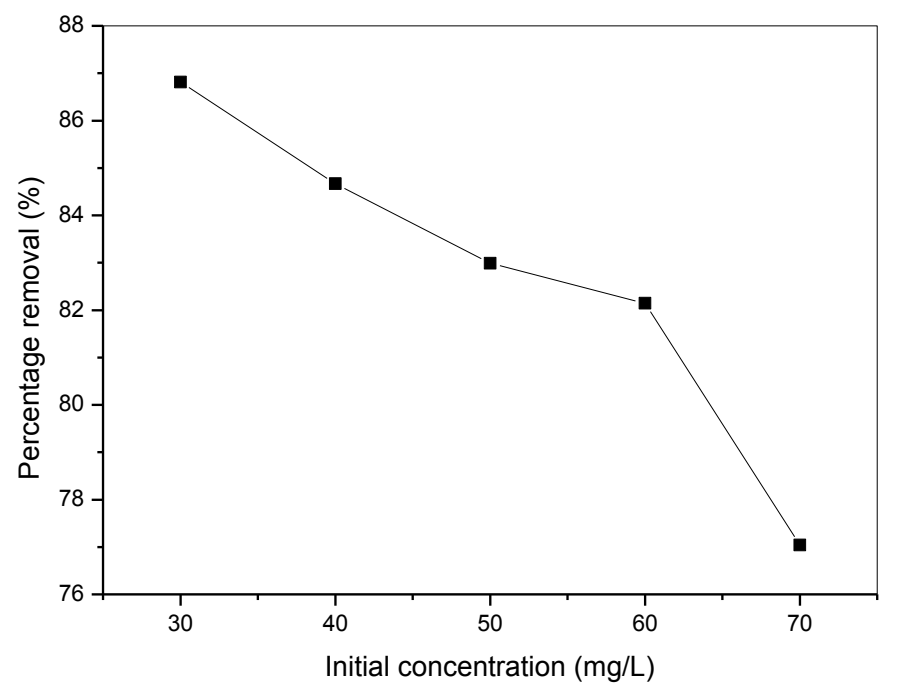

Figure 4. Effect of temperature on the adsorption of MR onto WPPP.

\section{Effect of pH}

The effect of $\mathrm{pH}$ on the adsorption capacity and percentage removal of methyl red onto WPPP was studied by preparing a dye solution of $50 \mathrm{mg} / \mathrm{L}$ concentration and different $\mathrm{pH}$ values (2 to 10). $100 \mathrm{ml}$ of each of the solution was added to $1 \mathrm{~g}$ of the adsorbent and agitated at the contact time of optimum adsorption at room temperature.

The result of the effect of solution $\mathrm{pH}$ on methyl red adsorption is illustrated in Fig. 5. It was observed that the adsorption capacity (figure not shown) and the percentage removal of the methyl red dye by the WPPP decreased from 4.53 to $4.15 \mathrm{mg} / \mathrm{g}$ and from 90.5 to $82.9 \%$ respectively as $\mathrm{pH}$ increases from 2 to 10 . The optimum sorption was found at $\mathrm{pH} 2$. The decrease in percentage removal and adsorption capacity with increase in $\mathrm{pH}$ maybe attributed to the reason that at high $\mathrm{pH}$ values of the solution, the presence of excess hydroxyl ion in the solution competes with the anionic groups of the methyl red dye for the adsorption sites on the adsorbent surface. While at low $\mathrm{pH}$ values, the negative charges in the solution decreases and the adsorbent surface is more positively charged, thus enhancing attraction of more amounts of the anions of the methyl red dye [27]. 


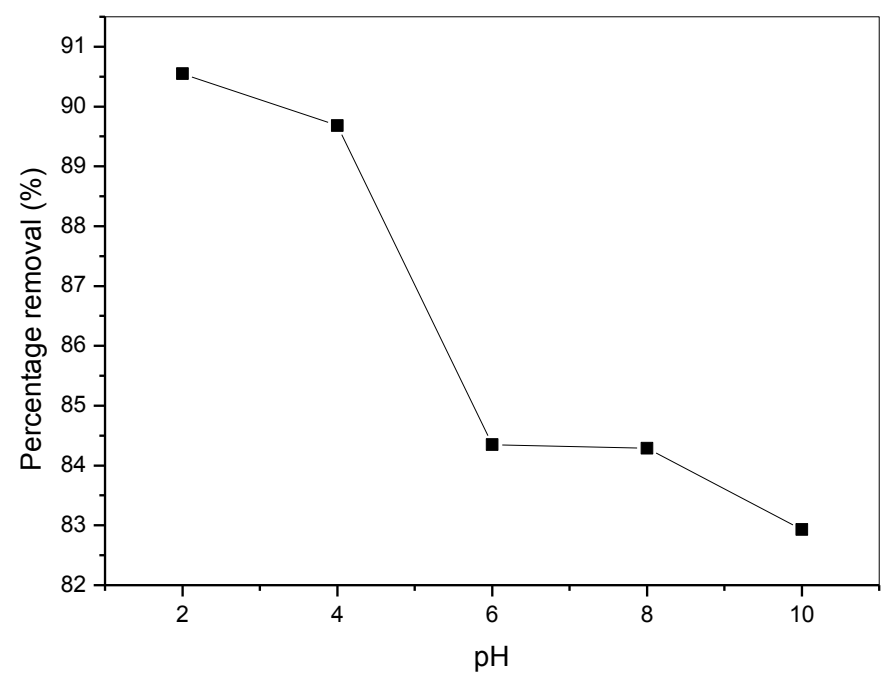

Figure 5. Effect of $\mathrm{pH}$ on the adsorption of MR onto WPPP.

\section{Adsorption Equilibrium Study}

The adsorption isotherm is the relationship between the amount of a substance adsorbed at a constant temperature and its concentration in the equilibrium solution [13]. Equilibrium adsorption isotherm equations are used to analyze the experimental adsorption data. The Langmuir and Freundlich models were adopted to analyze the adsorption data obtained. The parameters derived from these models are important in providing information on the adsorption mechanism, surface characteristics and affinities of the adsorbent [13].

To understand the nature of the interaction between the adsorbent WPPP and the methyl red dye, the linearized forms of the Langmuir and Freundlich isotherms are used to analyze the experimental data obtained.

The linearized form of the Langmuir isotherm equation is as show in equation 3 below:

$$
\frac{C \theta}{q \theta}=\frac{i}{b}\left(\frac{1}{q m}\right)+\frac{C e}{q m}
$$

where $\mathrm{C}_{\mathrm{e}}$ is the equilibrium concentration $(\mathrm{mg} / \mathrm{L}), \mathrm{q}_{\mathrm{e}}$ is the amount of the dye adsorbed at equilibrium (mg/g) and $\mathrm{q}_{\mathrm{m}}$ and $b$ are Langmuir constants which are related, respectively, to the adsorption efficiency and adsorption energy. A plot of $\mathrm{C}_{\mathrm{e}} / \mathrm{q}_{\mathrm{e}}$ against $\mathrm{C}_{\mathrm{e}}$ for the Langmuir isotherm is as shown in Figure 6. Where $1 / \mathrm{q}_{\mathrm{m}}$ and $1 /\left(\mathrm{bq}_{\mathrm{m}}\right)$ are the slope and intercept respectively. The values of $\mathrm{q}_{\mathrm{m}}$ and $b$ were calculated from the slope and intercept of the plot, and their values (with correlation coefficient, $\mathrm{R}^{2}$ ) are as shown in the Table 1 .

The Freundlich isotherm model is an empirical equation that can be used for non-ideal sorption involving a heterogeneous adsorption (13). The linear form of the equation is given below:

$$
\log q e=\log K f+\left(\frac{1}{n}\right) \operatorname{LOg} C e
$$

where $\mathrm{q}_{\mathrm{e}}$ is the amount of dye adsorbed at equilibrium, $\mathrm{C}_{\mathrm{e}}$ is the concentration of the dye solution at equilibrium (adsorption capacity) $1 / \mathrm{n}$ is a constant (representing adsorption intensity). The plot of $\log \mathrm{q}_{\mathrm{e}}$ versus $\log \mathrm{C}_{\mathrm{e}}$ is a straight line graph as shown in Fig. $7 . \log \mathrm{K}$ and $1 / \mathrm{n}$ are the intercept and slope respectively. The values of $K$ and $1 / n$, given in Table 1 , were calculated from the intercept and slope respectively of the plot.

The Langmuir and Freundlich isotherm constants are presented in Table 1. From this Table, it can be seen that the regression correlation coefficient $\left(R^{2}\right)$ of the Freundlich equation $\left(R^{2}=0.9777\right)$ is more linear when compared with that of the Langmuir equation $\left(R^{2}=0.898\right)$ implying that the adsorption isotherm data are well fitted by the Freundlich isotherm. The fact that the Freundlich 
isotherm fits the experimental data very well may be due to the heterogeneity of the surface of WPPP because application of the Freundlich equation involves the assumption that the surface is heterogeneous.

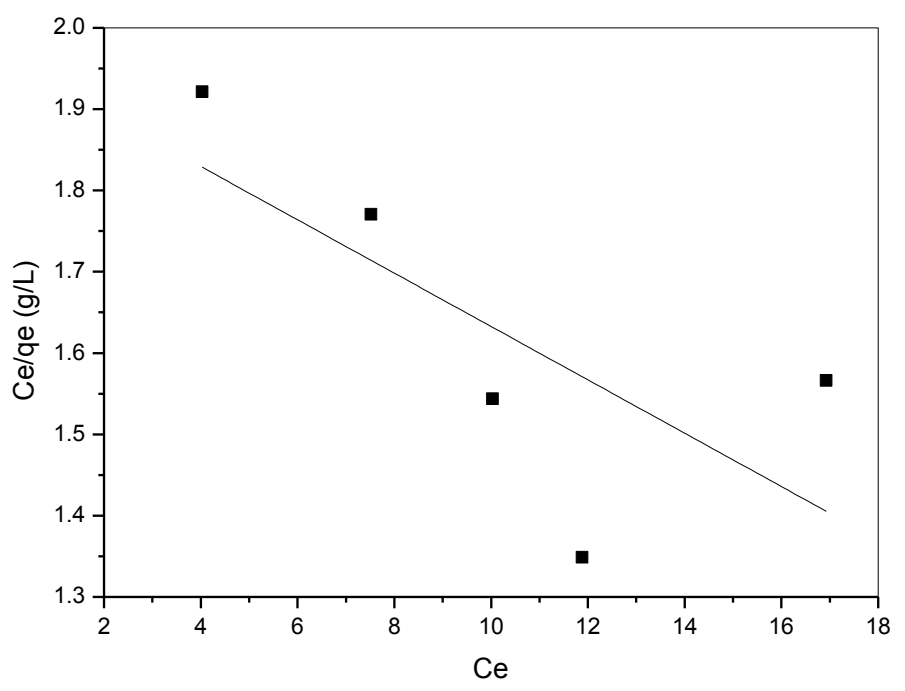

Figure 6. Langmuir plot for the adsorption of MR onto WPPP.

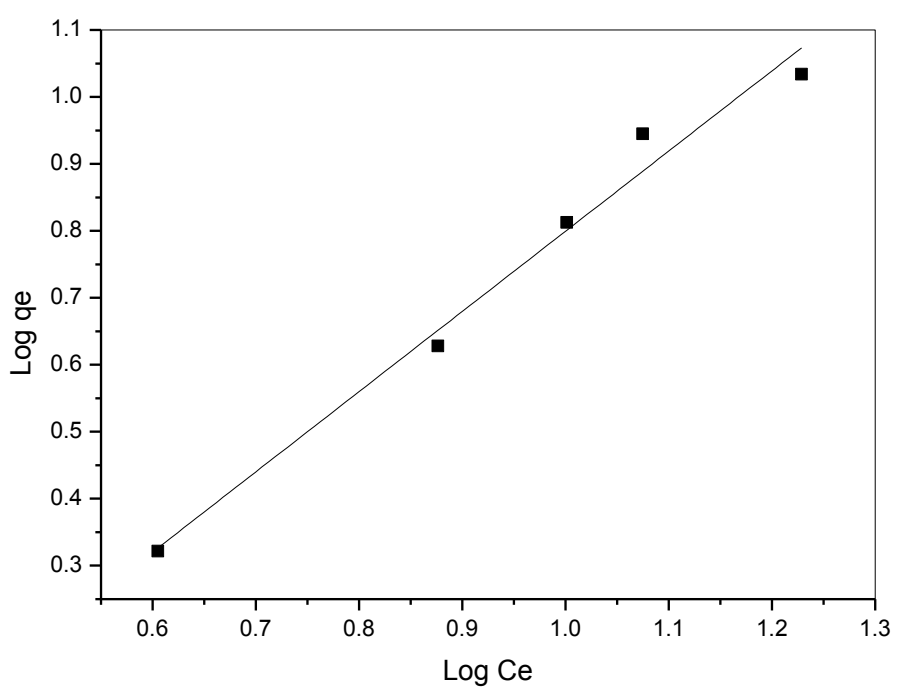

Figure 7. Freundlich plot for the adsorption of MR onto WPPP.

Table 1. Langmuir and Freudlich isotherm parameters for the adsorption of MR onto WPPP

\begin{tabular}{|c|c|c|c|c|c|}
\hline \multicolumn{2}{|c|}{ Langmuir } & \multicolumn{3}{c|}{ Freundlich } \\
\hline $\mathrm{Q}_{\mathrm{m}}(\mathrm{mg} / \mathrm{g})$ & $\mathrm{b}$ & $\mathrm{R}^{2}$ & $\mathrm{n}$ & $\mathrm{K}_{\mathrm{f}}(\mathrm{mg} / \mathrm{g})$ & $\mathrm{R}^{2}$ \\
\hline 30.48 & 0.017 & 0.898 & 1.517 & 0.835 & 0.9777 \\
\hline
\end{tabular}

\section{Adsorption Kinetics}

The pseudo-first order, pseudo-second order kinetics model were used to study the adsorption kinetics and to compute the extent of uptake in the adsorption process. equation:

The linear form of the pseudo-first order kinetic model is represented by the following 


$$
\log \left(\mathrm{q}_{\mathrm{e}}-\mathrm{q}_{\mathrm{t}}\right)=\log \mathrm{q}_{\mathrm{e}}-\mathrm{k}_{1} \mathrm{t} / 2.303
$$

where $\mathrm{q}_{\mathrm{e}}$ and $\mathrm{q}_{\mathrm{t}}$ are the values of amount of the dye adsorbed per unite mass on the adsorbent at equilibrium and at various time $\mathrm{t}$, respectively. $\mathrm{k}_{1}$ is the pseudo - first order adsorption rate constant $\left(\mathrm{min}^{-1}\right)$. The values of $\mathrm{k}_{1}$ and the calculated $\mathrm{q}_{\mathrm{e}}$ are determined from the slope and intercept respectively of the linear plot of $\log \left(\mathrm{q}_{\mathrm{e}}-\mathrm{q}_{\mathrm{t}}\right)$ versus $\mathrm{t}$.

The pseudo - second order kinetic model is expressed by as:

$$
\frac{t}{q_{t}}=\frac{1}{K_{2} q^{2}}+\frac{1}{q_{e}} t
$$

where $\mathrm{k}_{2}$ is the pseudo - second order adsorption rate constant $\left(\mathrm{g} / \mathrm{mg} / \mathrm{min}\right.$ and $\mathrm{q}_{\mathrm{e}}$ is the amount of dye adsorbed $(\mathrm{mg} / \mathrm{g})$ on the adsorbent at equilibrium. The initial adsorption rate, $\left(\mathrm{h}=\mathrm{mg} \cdot \mathrm{g}^{-1}\right.$. $\left.\mathrm{Min}^{-1}\right)$ is expressed as:

$$
\mathrm{h}=\mathrm{k}_{2} \mathrm{qe}^{2}
$$

The plot of $t / q_{t}$ versus $t$ gives a linear relationship which allows computation of $k_{2}, h$ and calculated $\mathrm{q}_{\mathrm{e}}$.

The applicability of these models is based on the judgment on the respective correlation coefficient $\left(R^{2}\right)$ and the agreement between the experimental and calculated value of $\mathrm{q}_{\mathrm{e}}$.

Fig. 8 and Fig. 9 show the pseudo - first order and second order kinetics for the adsorption of MR by WPP. The pseudo - first order rate constant $\left(\mathrm{k}_{1}\right)$ and $\mathrm{q}_{\mathrm{e}}$ determined from the model as well as the correlation coefficient of the plot are presented in Table 2. Fig. 8 and Table 2 show that the relationship between the dye diffusivity, $\operatorname{Iog}\left(\mathrm{q}_{\mathrm{e}}-\mathrm{q}_{\mathrm{t}}\right)$ and time $\mathrm{t}$, is non - linear with a very low correlation coefficient $\left(R^{2}=0.005\right)$. It is also observed that the calculated $\mathrm{q}_{\mathrm{e}}$ values did not agree with the experimental $\mathrm{q}_{\mathrm{e}}$ since the calculated $\mathrm{q}_{\mathrm{e}}$ values were neither equal nor reasonably close to the experimental $\mathrm{q}_{\mathrm{e}}$ values (Table 2). Therefore, the pseudo - first order model was inadequate in representing the adsorption of MR onto WPPP.

The pseudo - second order rate constants $\mathrm{k}_{2}$, and $\mathrm{q}_{\mathrm{e}}$ determined from the model, as well as the correlation coefficient are presented in Table 2. It is observed from Table 2 and Fig. 9 that there is good agreement between the calculated $\mathrm{q}_{\mathrm{e}}$ values and the experimental $\mathrm{q}_{\mathrm{e}}$ values i.e. $\mathrm{q}_{\mathrm{e}}$ (cal.) and $\mathrm{q}_{\mathrm{e}}$ (expt.). Table 2 also reveals a very high correlation value $\left(\mathrm{R}^{2}=0.9999\right)$ for the adsorption of MR by WPPP. It is therefore evident that the pseudo - second order model is the best fit kinetic model in describing the adsorption processes of MR onto WPPP.

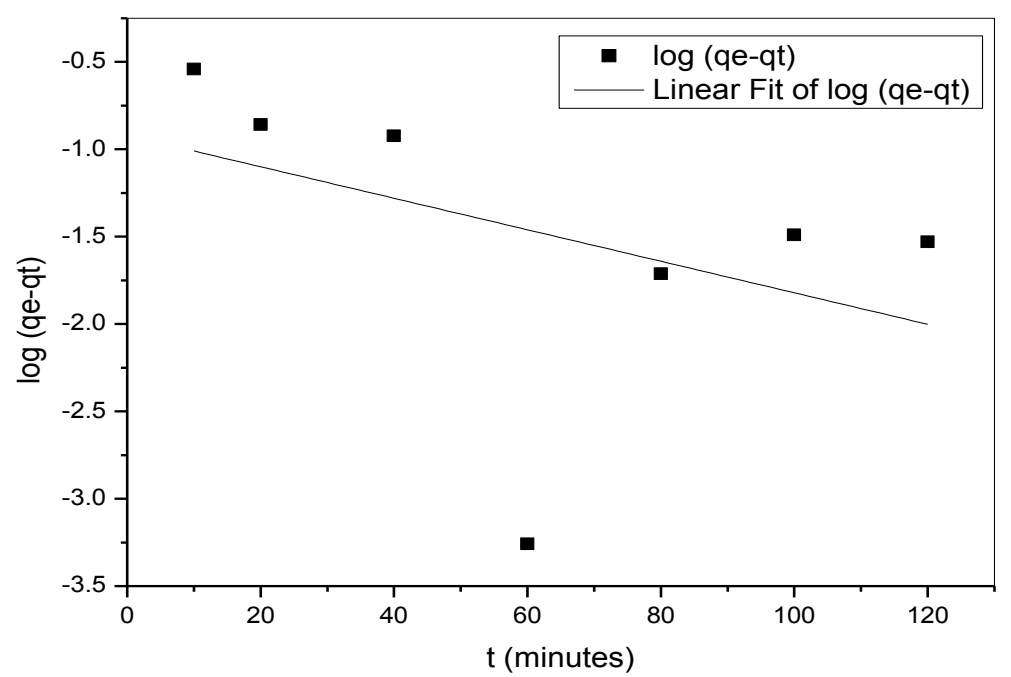

Figure 8. Pseudo-first order kinetics plot for the adsorption of MR onto WPPP. 


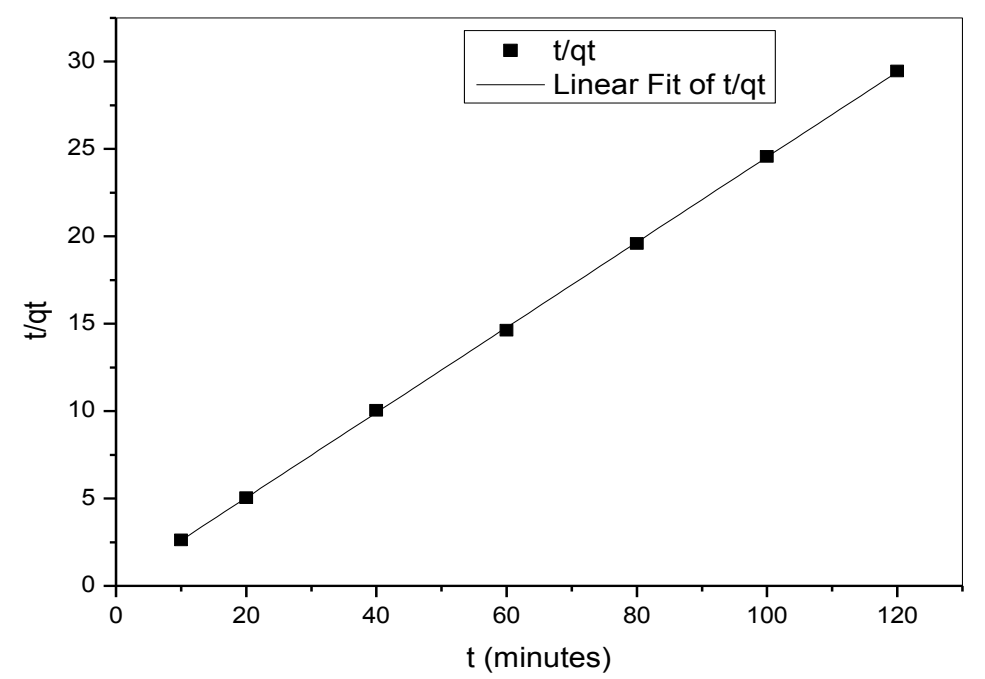

Figure 9. Pseudo-second order kinetics for the adsorption of MR onto WPPP.

Table 2. Pseudo - first order and second order kinetic model parameters.

\begin{tabular}{|c|c|c|c|c|c|c|c|}
\hline \multicolumn{4}{|c|}{ Pseudo - First Order Model } & \multicolumn{3}{c|}{ Pseudo - second Order Model } \\
\hline $\begin{array}{c}\mathrm{q}_{\mathrm{e}} \\
(\mathrm{exp})\end{array}$ & $\begin{array}{c}\mathrm{k}_{1} \\
\left(\mathrm{~g} \cdot \mathrm{mg}^{-1}\right. \\
\left.\mathrm{mg} / \mathrm{g} \mathrm{min}^{-1}\right)\end{array}$ & $\begin{array}{c}\mathrm{q}_{\mathrm{e}}(\mathrm{cal}) \\
(\mathrm{mg} / \mathrm{g})\end{array}$ & $\mathrm{R}^{2}$ & $\begin{array}{c}\mathrm{h} \\
\left(\mathrm{mg}^{-1} \mathrm{~g}^{-1}\right. \\
\left.\mathrm{min}^{-1}\right)\end{array}$ & $\begin{array}{c}\mathrm{k}_{2} \\
\left(\mathrm{~g} \cdot \mathrm{mg}^{-1}\right. \\
\left.\mathrm{min}^{-1}\right)\end{array}$ & $\begin{array}{c}\mathrm{q}_{\mathrm{e}}(\mathrm{cal}) \\
(\mathrm{mg} / \mathrm{g})\end{array}$ & $\mathrm{R}^{2}$ \\
\hline 4.102 & 0.021 & 0.020 & 0.005 & 15.858 & 0.348 & 4.104 & 0.9999 \\
\hline
\end{tabular}

\section{Adsorbent characterization}

The FTIR spectra of WPPP before and after adsorption (Fig.10-11) of MR dye were analyzed to determine the vibration frequency changes in their functional groups. For WPPP before adsorption, various peaks are at $3421.13 \mathrm{~cm}^{-1}$ (O-H stretch, H-bonded), $2932 \mathrm{~cm}^{-1}$ (C-H stretch from alkane), $1716.94 \mathrm{~cm}^{-1}$ and $1734.10 \mathrm{~cm}^{-1}(\mathrm{C}=\mathrm{O}$ stretch$), 1653.61 \mathrm{~cm}^{-1}(\mathrm{C}=\mathrm{C}$ stretch $), 1521.90 \mathrm{~cm}^{-1}$ and $1534.06 \mathrm{~cm}^{-1}\left(\mathrm{~N}-\mathrm{O}\right.$ asymmetric stretch), $1457.31 \mathrm{~cm}^{-1}(\mathrm{C}-\mathrm{H}$ bend $), 1418.95 \mathrm{~cm}^{-1}\left(\mathrm{CH}_{3}\right)$, $1154.94 \mathrm{~cm}^{-1}$ (C-N stretch), $1023.28 \mathrm{~cm}^{-1}$ (C-O stretch), $930.01 \mathrm{~cm}^{-1}$ (O-H bend from carboxylic acid), $860.83 \mathrm{~cm}^{-1}$ (C-Cl stretch) and $526.16 \mathrm{~cm}^{-1}$ (C-Br) [28]. After adsorption of MR dyes it was found out that most of the functional groups were affected after the uptake process. This is judged from shifts in the position of some of the functional groups to lower or higher frequency or band intensity before and after MR adsorption. The functional groups that moved to lower frequency or band intensity includes: C-O, N-O and C-Cl from $1023.28,1521.90$ and $860.83 \mathrm{~cm}^{-1}$ to 1018.88 , and 1342.78 and $769.80 \mathrm{~cm}^{-1}$ respectively. The functional groups that moved to higher frequency or band intensity includes: $\mathrm{O}-\mathrm{H}, \mathrm{C}=\mathrm{C}$, and $\mathrm{C}-\mathrm{Br}$ from $3421.13,1647.25$ and $526.16 \mathrm{~cm}^{-1}$ to 3517.48 , 1652.54 and $648.42 \mathrm{~cm}^{-1}$ respectively. This indicates involvement of these groups for MR binding to WPPP [29].

Also, Fig. 12 shows the SEM images of WPPP powder. It can be observed from Fig. 12 that the external surface of WPPP powder is very irregular with rough edges and presence of few pores. 


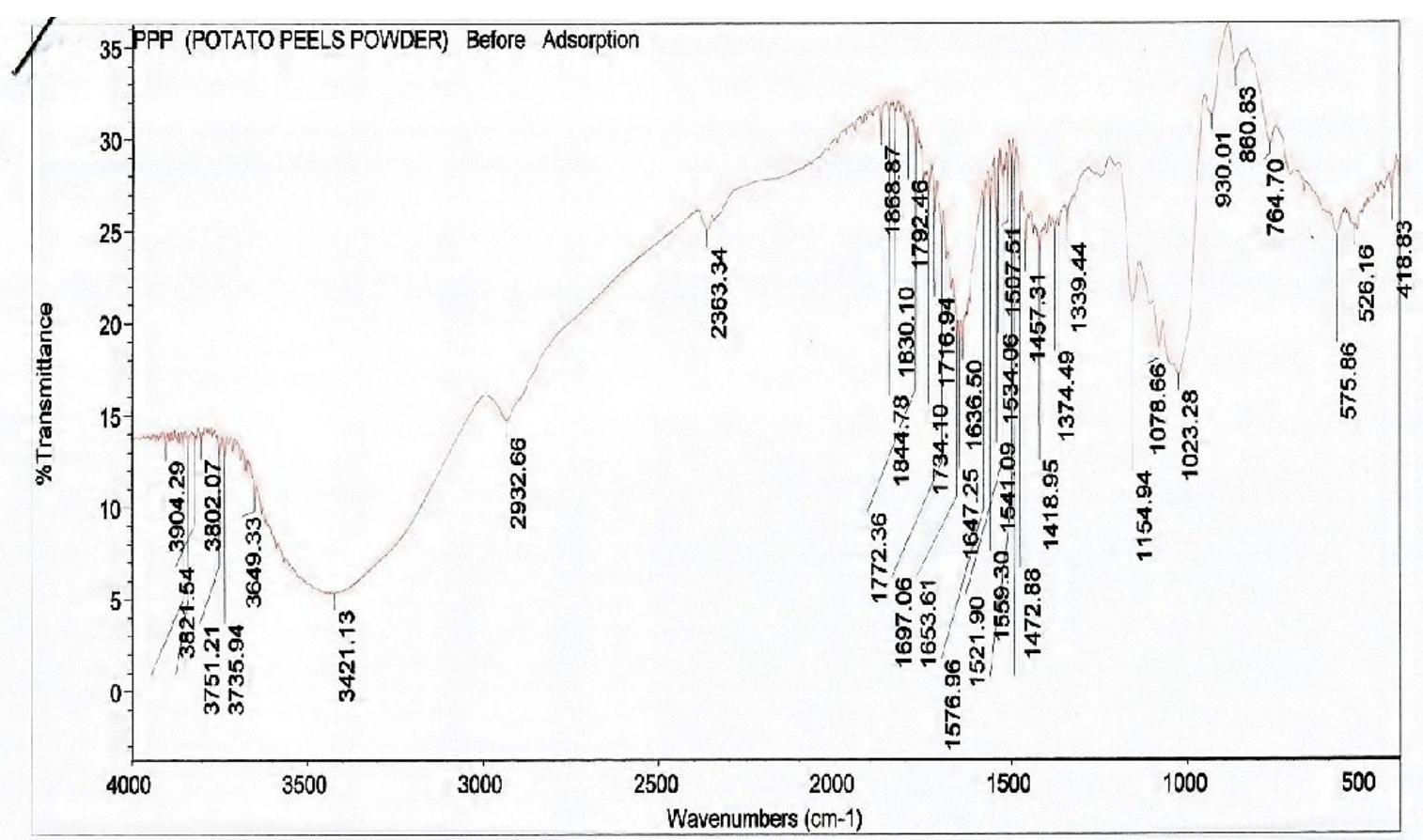

Figure 10. FTIR spectra of WPPP before adsorption.

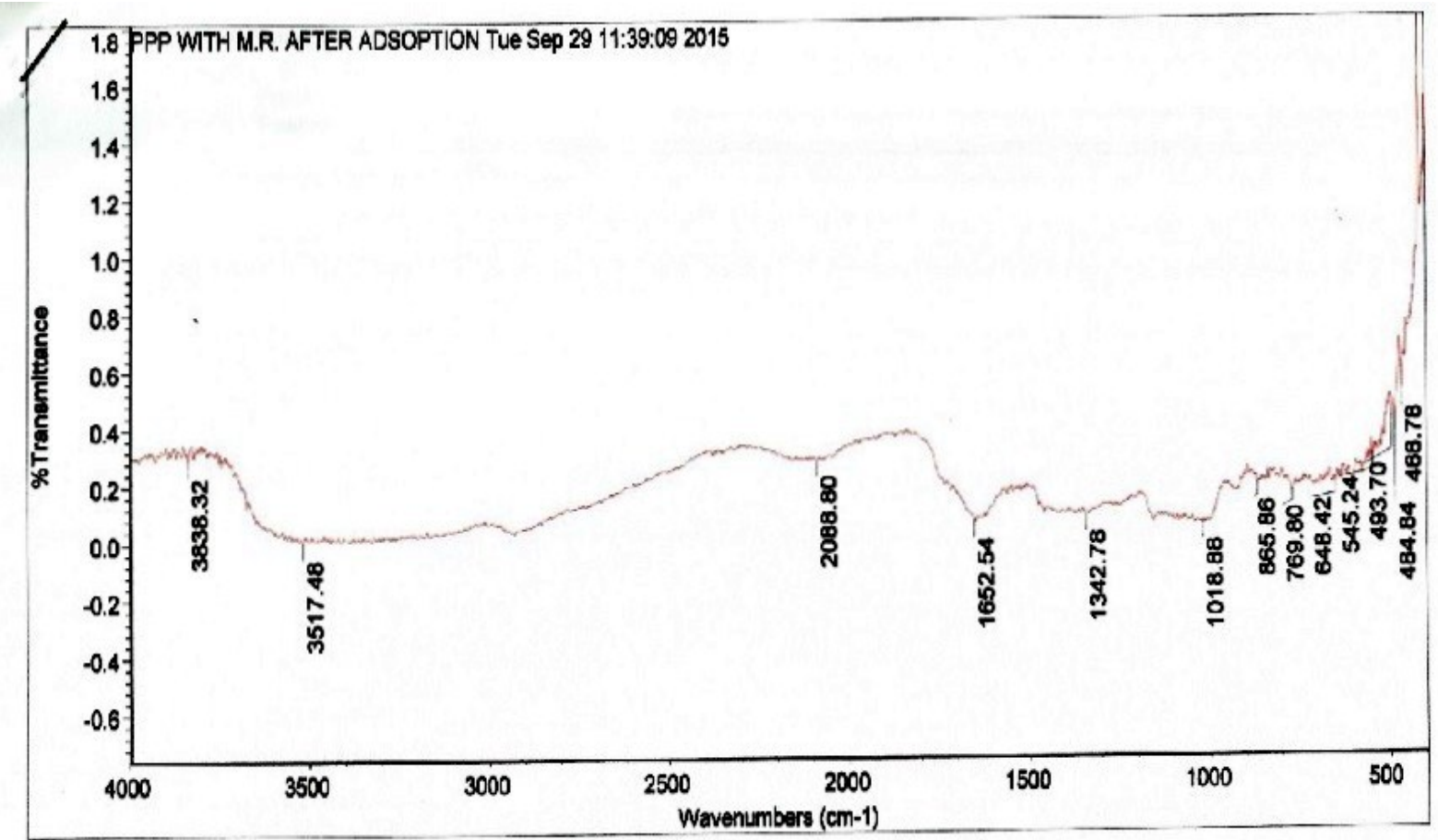

Figure 11. FTIR spectra of WPPP after adsorption. 


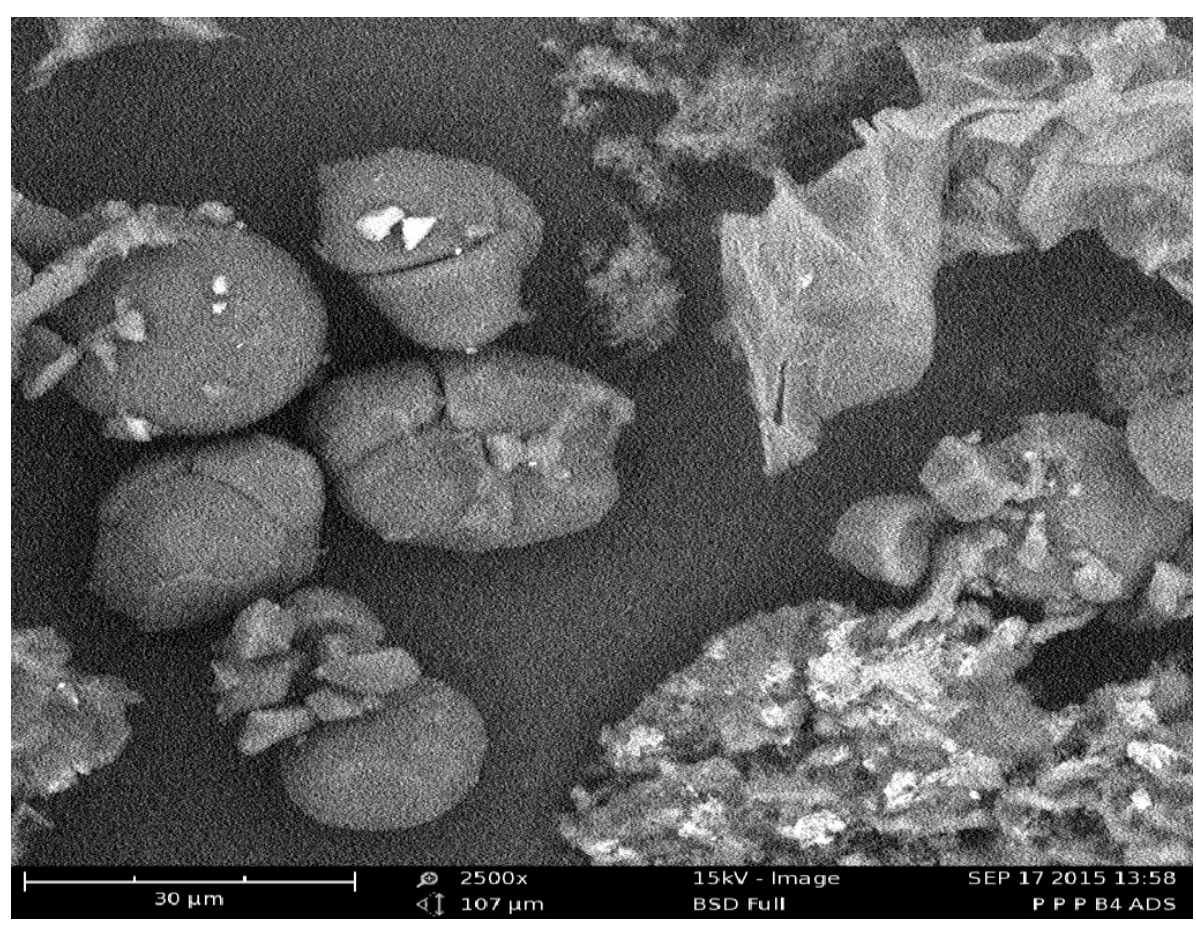

Figure 12. SEM micrograph of WPPP powder surface at magnification $2500 \times$.

\section{Conclusion}

The potential of white potato peels (WPP) powder as an effective adsorbent for the removal of methyl red dye from aqueous medium has been identified. The adsorption of methyl red dye onto WPPP was found to be influenced by contact time, adsorbent dose, initial concentration, temperature and initial $\mathrm{pH}$ of solution. Increasing contact time increased the amount of MR dye adsorbed up to an optimum value, beyond which the amount of dye adsorbed decreased. Increasing initial dye concentration, temperature and $\mathrm{pH}$ led to increasing amount of MR adsorbed onto the WPPP adsorbent. The kinetic studies revealed that the adsorption of MR dyes onto WPPP adsorbent followed the pseudo - second order kinetic model. The study on equilibrium sorption revealed that the Freundlich isotherm model gave the best fit to the experimental data.

\section{References}

[1] W. Delee, C. Oneil, F.R Hawkes, Anaerobic treatment of textile effluents: A review, Journal of chemical technology and biotechnology. 73(4) (1998) 323-335.

[2] S.K. Bajpai, A. Jain, Equilibrium and thermodynamic studies for adsorption of crystal violet onto spent tea leaves, Water. 4 (2012) 52-57.

[3] G. Muthuraman, T.T. Tjoon, Extraction of methyl red from industrial wastewater using xylene as an extractant, Progress in Natural Science. 19 (2009) 1215-1225.

[4] A. Azraa et al., Kinetics and thermodynamics studies on the adsorption of direct dye onto a novel green adsorbent developed from uncarie gambir extract, Journal of Physical Science. 23(1) (2012) 1-13.

[5] R. Malik, D.S. Rametke, S.R. Wate, Adsorption of malachite green on groundnut shell waste based powdered activated carbon, J. Was. Manag. 27 (2006) 1-8

[6] G. Crini, Non convectional low cost adsorbent for dye removal: A review, Bioresource technology. 97(9) (2006) 1061-1085.

[7] M.A. Al-Ghouti et al., The removal of dyes from textile wastewaters: a study of diatomaceous earth, J. Env. Manag. 69 (2003) 230-237. 
[8] C. $\mathrm{Ng}$ et al., Freundlich adsorption isotherms of agricultural by product based powdered activated carbons in a geosmin water system, Bioresource Technology. 85(2) (2002) 131-135.

[9] T. Santhi, S. Manonmani, T. Smitha, Removal of methyl red from aqueous solution by activated carbon prepared from the Annona squmosa seed by adsorption, Chemical Engineering Bulletin. 14 (2010) 11-18.

[10] K. Haitham, S. Razak, M.A. Nawi, Kinetics and isotherm studies of methyl orange adsorption by a highly recyclable immobilized polyaniline on a glass plate, Arabian Journal of Chemistry. (2014) 1-8.

[11] A. Kausar, H.N. Bhatti, G. Mackinnon, Equilibrium, kinetics and thermodynamic studies on the removal of U (VI) by low cost agricultural waste, Colloids and Surfaces B: Biointerfaces. 111 (2013) 111-124.

[12] B. Singha, S.K. Das, Adsorptive removal of $\mathrm{Cu}$ (ii) from aqueous solution and industrial effluent using natural agricultural wastes, Colloids and Surfaces B: Biointerfaces. 107 (2013) 97-106.

[13] O. Abdelwahab, Kinetic and isotherm studies of copper (ii) removal from waste water using various adsorbents, Egyptian J. Aqu. Res. 33 (2007) 136.

[14] X.S. Wang, Y. Qin, Equilibrium sorption isotherms for $\mathrm{Cu} 2+$ on rice bran, Process Biochemistry. 40(2) (2005) 677-680.

[15] G. Muthuraman, T.T. Tjoon, Extraction of methyl red from industrial wastewater using xylene as an extractant, Progress in Natural Science. 19 (2009) 1215-122.

[16] A. Kausar, H.N. Bhatti, G. Mackinnon, Equilibrium, kinetics and thermodynamic studies on the removal of U (VI) by low cost agricultural waste, Colloids and Surfaces B: Biointerfaces. $111(2013) 124$.

[17] T. Santhi, S. Manonmani, T. Smitha, Removal of methyl red from aqueous solution by activated carbon prepared from the Annona squmosa seed by adsorption, Chemical Engineering Bulletin. 14 (2010) 11-18.

[18] B.A. Fahim, A. Maimuna, M.A. Zainal, Dyes removal from textile wastewater using orange peels, International Journal of Scientific and Technology Research. 2(9) (2013) 47-50.

[19] A.K. Asiagwu, H.I. Owamah, V.O. Illoh, Kinetics and thermodynamic models for the removal of amino-phenol (dye) from aqueous solutions using groundnut (arachis hypogea) shells as the biomass, Advances in Applied Science Research. 3(4) (2012) 2257-2265.

[20] W. Sumanjit, T.P.S. Walia, K. Ravneet, Removal of health hazards causing acidic dyes from aqueous solution by the process of adsorption, Online Journal of Health and Allied Sciences. 6(3) (2007) 1-10.

[21] S.P. Kumar et al., Adsorption of basic dye onto raw and surface modified agricultural waste, Evn. Progress and Sustainable Energy. 33(1) (2013) 87-98.

[22] P. Satish et al., Kinetics of adsorption of crystal violet from aqueous solutions using different materials, Inter. J. Env. Sci. 1(6) (2011) 1116-1134.

[23] A. EL-Maghraby, H.A. EL-Deeb, Removal of a basic dye from aqueous solution by adsorption using rice hulls, Global Nest Journal. 13(1) (2011) 90-98.

[24] K.S. Bharathi, S.T. Ramesh, Removal of dyes using agricultural waste as low cost adsorbents: A review, Appl. Water Sci. 3 (2013) 773-790.

[25] T.C. Chandra et al., Asorption of basic dye onto activated carbon prepared from durian shell: Studies of adsorption equilibrium and kinetics, Chemical Engineering Journal. 127(1-3) (2007) 121-129. 
[26] A. Ozcan et al., Modification of bentonite with a cationic surfactant: An adsorption study of textile dye Reactive Blue 19, J. Hazard. Mater. 140(1) (2007) 173-179.

[27] C. Namasivayam, D. Kavitha, Removal of congo red from water by adsorption onto activated carbon prepared from coir pith, agricultural solid waste, Dyes Pigments. 54 (2002) 47-58.

[28] M.L. Gary et al., Spectroscopy: Infra-red spectroscopy, fourth ed., Brooks/Cole, Bellingham, Washington, 2010, pp. 15-87.

[29] N. Sharma, B.K. Nnadi, Utilization of sugarcane baggase, an agricultural waste to remove malachite green dye from aqueous solution, J. Mater. Environ. Sci. 4(6) (2013) 1052-1065. 